\title{
AN ATTEMPT TO ASSESS THE INTELLIGENCE OF YOUNG CHILDREN BY USE OF A CONDITIONED REFLEX
}

\author{
BY \\ JOHN RENDLE-SHORT \\ From the Department of Child Health, University of Sheffield
}

(RECEIVED FOR PUBLICATION APRIL 19, 1960)

Krasnogorski (1913), who was working with Pavlov in St. Petersburg, described his experiments on establishing conditioned reflexes in children. His methods were expanded by Mateer (1918) whose paper will be described later. No further relevant work on the subject was published until Pavlov's famous book on Conditioned Reflexes (Pavlov, 1927). This work is well known and only a brief summary of it will be given here. Pavlov distinguished between inborn and conditioned reflexes. If food is placed in a dog's mouth, the dog salivates. That is an inborn reflex. If the dog salivates when he hears the footsteps of his master coming to feed him, that is a conditioned reflex. A conditioned reflex must te founded on an inborn reflex or a new stimulus can be used for a well-established conditioned reflex.

There are three components of a conditioned reflex: the unconditioned stimulus, which gives rise to the unconditioned reflex, and the conditioned stimulus which, after being paired with the unconditioned stimulus, elicits the same response. In the example given above the unconditioned stimulus is the food, the reflex the salivation and the conditioned stimulus the footsteps. When conditioning is established the reflex will appear if the conditioned stimulus alone is exhibited. Pavlov stressed that successful conditioning could only be expected under optimal circumstances. Irrelevant stimuli such as fear, noise or the desire to micturate tend to prevent the establishment of conditioned reflexes in animals. If a conditioned reflex is not periodically reinforced by the reintroduction of the unconditioned stimulus it gradually becomes extinct. This fading away of the reflex is known as deconditioning. Even after deconditioning, however, the reflex may spontaneously regenerate with the passage of time.

Pavlov's book referred only to experiments on animals, but other workers tried similar experiments on children. One of the earliest attempts to utilize the concept of the conditioned reflex in diagnosis was reported by Aldrich (1928). He conditioned pain, in the form of a pin-scratch on the sole of the foot, and the sound of a dinner gong, in order to demonstrate hearing in a 3-month-old infant.

It was found that the younger the child, the harder he was to condition. Wenger (1943) described some controlled experiments in which he tried to condition infants to blink in response to an electric shock which had been coupled with a bright light shining into their eyes. Later some of the infants blinked with the shock alone, but only after they had received up to 240 stimulations administered over several days. Even then not all the infants could be conditioned. In early infancy 100-300 paired stimulations may be required to establish a conditioned reflex, whereas by the age of 1 year, two or three stimulations will suffice (Gesell, 1948).

While there is undoubtedly a connexion between ease of conditioning and age, there has been some doubt as to whether ease of conditioning can be correlated with intelligence. Gesell and Ilg (1937), when studying the feeding behaviour in infants, noticed that normal infants became excited when they observed their food being prepared. As this occurred first at the age of about 16 weeks in normal infants, but later in mentally retarded infants, the observation has been used to assess intelligence. This is an example of a natural conditioned reflex which can be used as a developmental test. On the other hand Campbell and Hilgard (1936) using the conditioned eye-blink in 63 university students, found that there were wide individual differences in the ease with which a conditioned response could be formed. After performing intelligence tests on the students, they came to the conclusion that intelligence was not significantly related to the ease 


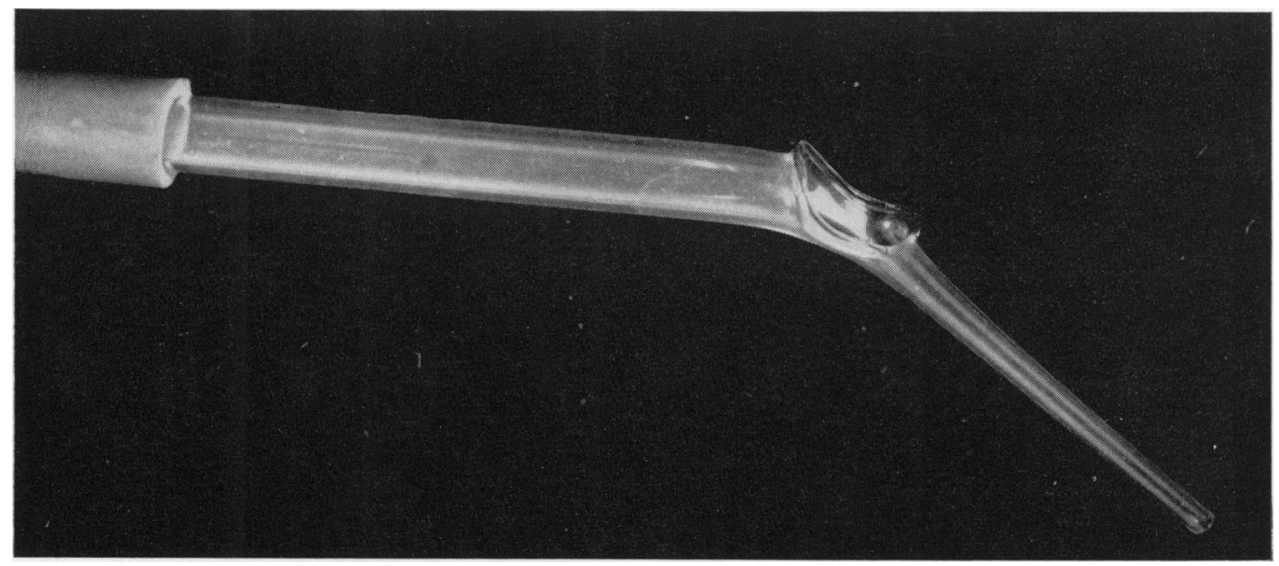

Fig. 1.-The puff gun.

of conditioning. This work, however, is not strictly relevant as it concerns adults and the differences in intelligence found were not very great.

Birch and Demb (1959) performed some experiments on 26 mentally retarded children. The conditioned reflex they used was a mild electric shock and a light. Changes in the skin reaction were recorded by a psychogalvanometer. The children were all over 6 years of age, most of them being between 10 and 16 years old. The intelligence quotients ranged from 30-85 with an average of 50 . No correlation was found between the ease of conditioning and the intelligence quotient. Kodman, Fein and Mixson (1959) have also experimented with the psychogalvanometer in mentally defective children. They concluded that further inquiry is required 'into the relationship between ease of conditioning and the learning process in severely retarded children'.

It has been shown that audiometry by means of the 'peep-show technique' (Dix and Hallpike, 1947), and by psychogalvanometry (Bordley and Hardy, 1949), both of which utilize the principle of the conditioned reflex, are of little value in testing mentally retarded children, as they cannot easily be conditioned (Statten and Wishart, 1956).

The present viewpoint can be summarized in the words of Hilliard and Kirman (1957) who wrote, 'It can be said of mongols as of other imbeciles and idiots that inborn or unconditioned reflexes are present though possibly weaker than normal. On the other hand conditioned reflexes which form the basis of adaptive behaviour are established much more slowly and less surely'.

Thus there is good evidence that conditioned reflexes can be established in young children, and that the ease with which this can be done bears some relationship to age. The evidence as to whether there is any relationship to intelligence, however, is conflicting.

\section{The Present Experiment}

The experiments described in this paper were designed to find out: (1) the relationship between the development of a conditioned reflex and age in children with normal intelligence, (2) the relationship between a conditioned reflex and both age and intelligence in mentally retarded children, and (3) whether the time taken to establish a conditioned reflex could be used as a measure of intelligence.

According to Pavlov (1927) the easiest conditioned reflexes to establish are those associated with the alimentary tract and those concerned with the prevention of injury. In babies, apart from the excitation with feed reflex mentioned above, no alimentary reflex could easily be utilized in a clinical test. I tried several methods of establishing a conditioned reflex, such as banging a gong, and stimulating the sole of the foot with a jet of cold water to obtain a withdrawal reflex, or the administration of a slight electric shock just before shining a light into the eyes to obtain a pupillary reaction. These all failed and eventually the following test was devised.

The unconditioned or inborn reflex used was the eye blink when air was puffed into the face. The conditioned stimulus was the presentation of the 'gun' without any air being puffed, and the conditioned reflex was the eye blink before the air was puffed.

The details which follow describe an attempt to standardize the procedure so that comparison could be made between one child and another.

Detailed Description of the Test. The apparatus used (Fig. 1) consisted of a glass tube $18 \mathrm{~cm}$. in length tapered 
at one end to form a nozzle (bore approximately $1 \mathrm{~mm}$.) and bent $11 \mathrm{~cm}$. from the end to an angle of about 110 degrees. A side hole of about $1.5 \mathrm{~cm}$. diameter was made on the obtuse side of the bend. The glass tube was attached by rubber tubing to a cylinder of compressed air or oxygen which was fitted with a flow meter. When the gas was turned on it normally flowed out of the large side-hole in the glass tube (called the 'gun'). The 'gun' was 'fired' by occluding the hole with the thumb. Gas was then ejected through the nozzle.

The tests were performed as follows: The child sat on the mother's or nurse's knee facing the tester; the tester sat on another chair just in front of the child holding the 'gun' in one hand and a watch in the other. He was in easy reach of the gas cylinder so that he could regulate the rate of flow. The 'gun' was presented to the child at 15 -second intervals. That is to say the tester lifted it up and held it about $20 \mathrm{~cm}$. in front of the child's face, on a level with his eyes. This presentation was performed gently and evenly so as not to startle the child.

The first three times the 'gun' was presented, although the gas was turned on it was not 'fired', i.e. no puff of gas was blown into the child's eye. During these preliminary presentations careful watch was kept on the child's reactions to see whether he blinked or grimaced spontaneously. At the fourth presentation the 'gun' was aimed at the child's eye as before, and after a moment it was 'fired'. The child's reaction was observed. It was usually of the same pattern on each subsequent occasion. Care was taken to distinguish between the eye blink due to the puff of air, and a spontaneous blink. With practice this was not difficult, as the eye blink due to the puff was usually associated with some screwing up of the eyes involving both the lower and upper lid. This had quite a different appearance from a spontaneous blink.

If the effect produced by the puff was insufficient, the gas flow was increased; if it was too violent the flow was decreased. The flow required had to be determined by trial and error in each individual case. An initial flow of $41 . / \mathrm{min}$. was found to be suitable, but sometimes the rate had to be increased progressively as the test continued.

Subsequent puffs were each made in the same way as the first. Great care was taken to allow a moment to elapse after the child had been presented with the 'gun' and had obviously noticed it, but before the 'gun' was fired. It was during this moment that it was possible to observe whether or not the child had been conditioned by the previous puff or puffs.

On the presentation at which it was thought that the child was conditioned, a puff was given in the same way as previously to reinforce the conditioning. At the next presentation no puff was given. If the child was really conditioned, he again blinked without a puff being given. If, however, a mistake had been made, a further puff was given after a few seconds delay and conditioning proceeded with. The number of puffs required before a child was conditioned was counted as his score. It was found that the proportion of children conditioning after
20 puffs was too few to make it worthwhile continuing the test for longer than this.

After the child was conditioned, deconditioning was performed by continuing to present the 'gun' at 15 -second intervals as before, but without 'firing' it. The conditioned reflex often faded slowly, but the end point could be assessed with reasonable accuracy. Five presentations of the 'gun' were found to be all that was required for deconditioning. After this the results were unhelpful. If the end point of the test was not clear-cut the test was repeated after 20 minutes.

\section{Results}

In order to discover how normal children reacted to the test, it was performed on 168 children of apparently normal mentality between the ages of 5 months and 7 years. In 13 children the test had to be abandoned because of lack of co-operation or some other reason, leaving 155 children who are the subject of this part of the investigation. I performed a rough conventional developmental test first on each child to make sure that his intelligence corresponded with his chronological age. It is realized that the assessment of mental ability at this age is, at best, an inaccurate procedure, and some of the discrepancies in the results may be due to the fact that the child's intelligence was over or underestimated. Ideally the results of the puff test should be correlated with a formal intelligence test performed when the child is old enough. This investigation is proceeding.

The scattergram (Fig. 2) and Table 1 compiled from it give the results of the tests done on the $\mathbf{1 5 5}$ apparently normal children. Of the 12 children of 6 months and under, 11 could not be conditioned. This is the typical infantile response. Between the ages of $6 \frac{1}{2}$ and 12 months there were 49 children. Of these, 33 conditioned in less than 13 puffs, whereas 15 still gave the infantile type of reaction. One child conditioned in 16 puffs. Of the 32 children between $12 \frac{1}{2}$ and 18 months, all conditioned in 10 or less puffs, except for one child who required 19. Over the age of 18 months but under the age

TABLE 1

CORRELATION BETWEEN AGE AND EASE OF CONDITIONING IN 155 CHILDREN OF NORMAL INTELLIGENCE

\begin{tabular}{|c|c|c|c|c|c|}
\hline \multirow[t]{2}{*}{ Age } & \multicolumn{2}{|c|}{$\begin{array}{c}\text { Apparently } \\
\text { Normal } \\
\text { Range }\end{array}$} & \multicolumn{2}{|c|}{$\begin{array}{c}\text { Better or Worse } \\
\text { than } \\
\text { Normal Range }\end{array}$} & \multirow{2}{*}{$\begin{array}{c}\text { Total } \\
\text { No. of } \\
\text { Children }\end{array}$} \\
\hline & $\begin{array}{l}\text { No. of } \\
\text { Puffs }\end{array}$ & $\begin{array}{c}\text { No. of } \\
\text { Children }\end{array}$ & $\begin{array}{c}\text { No. of } \\
\text { Puffs }\end{array}$ & $\begin{array}{l}\text { No. of } \\
\text { Children }\end{array}$ & \\
\hline $\begin{array}{c}<6 \text { mths } \\
6 \frac{1}{2}-12 \text { mths } \\
12 \frac{1}{2}-18 \text { mths } \\
18 \frac{1}{2} \text { mths }-4 \text { yrs } \\
>4 \text { yrs }\end{array}$ & $\begin{array}{l}20+ \\
3-12 \\
2-10 \\
2-6 \\
2\end{array}$ & $\begin{array}{l}11 \\
33 \\
31 \\
45 \\
13\end{array}$ & $\begin{array}{c}12 \\
16-20 \\
19 \\
7-13 \\
4-5\end{array}$ & $\begin{array}{r}1 \\
16 \\
1 \\
2 \\
2\end{array}$ & $\begin{array}{l}12 \\
49 \\
32 \\
47 \\
15\end{array}$ \\
\hline
\end{tabular}




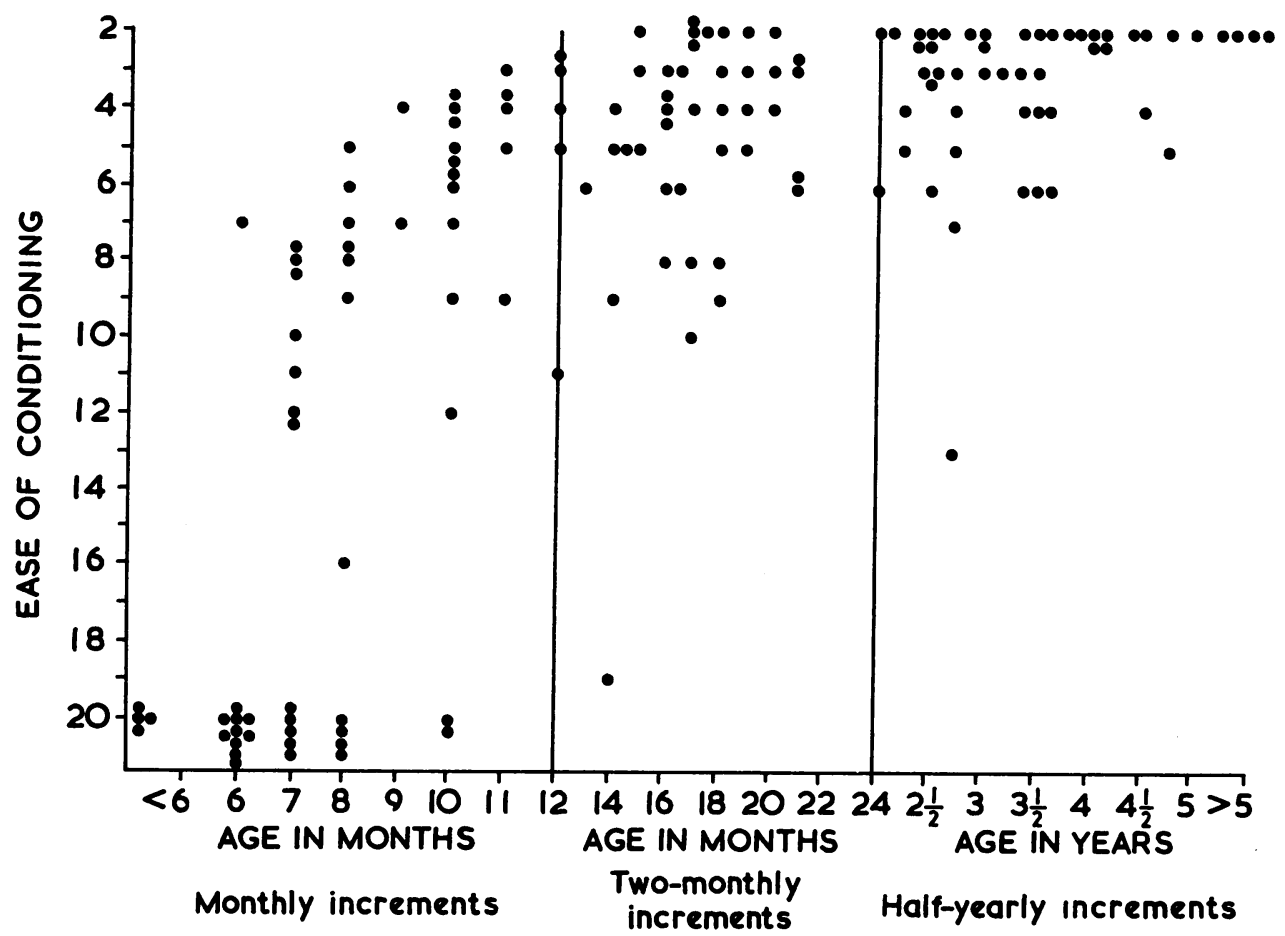

FIG. 2.-The puff test. Ease of conditioning compared with chronological age in 155 mentally normal children:

of 4 years, 45 children conditioned in between two and six puffs, but two required more. Of the 15 children over the age of 4 years, all but two conditioned in two puffs, which is the normal adult type of reaction.

In this experiment no child under the age of 14 months showed the typical adult type of reaction, and no child over 11 months showed the typical infantile type of reaction. From the point of view of the practical conduct of the test it will be seen that only two out of the 129 children who were successfully conditioned did so after 13 puffs.

So far I have successfully tested only 74 mentally defective children. Fig. 3 is a scattergram comparing ease of conditioning in mentally defective children with their chronological age. Fig. 4 shows ease of conditioning compared with approximate mental age. The former figure demonstrates the difficulty in conditioning these children, while the latter resembles the scattergram for normal children (Fig. 2).

\section{Discussion}

The puff test gave helpful results mainly between the ages of 6 months and 4 years. It so happens that this is an age group in which it is often difficult to assess intelligence.

The test only required a minimum of co-operation from the child and could be performed if the child looked at the 'gun' and did not cry or cover his eyes. No motor skill or educational knowledge was required, and the test could therefore be used in children with severe spasticity or deafness. Some athetoid children could not be tested owing to the difficulty in determining the end point. Another advantage of the test was that it was quick to perform; it never took longer than seven minutes and usually only two or three minutes.

I found no simple relationship between ease of deconditioning and age or intelligence. It did, however, give some indication of the fixity of the conditioning and for this reason it was of some value particularly in children who conditioned in two or three puffs.

Disadvantages and Difficulties. The test can only be performed on a child who can see and focus on the 'gun' and who has a normal corneal sensitivity. Most children laughed or smiled during the test, but a few cried or covered their eyes. 

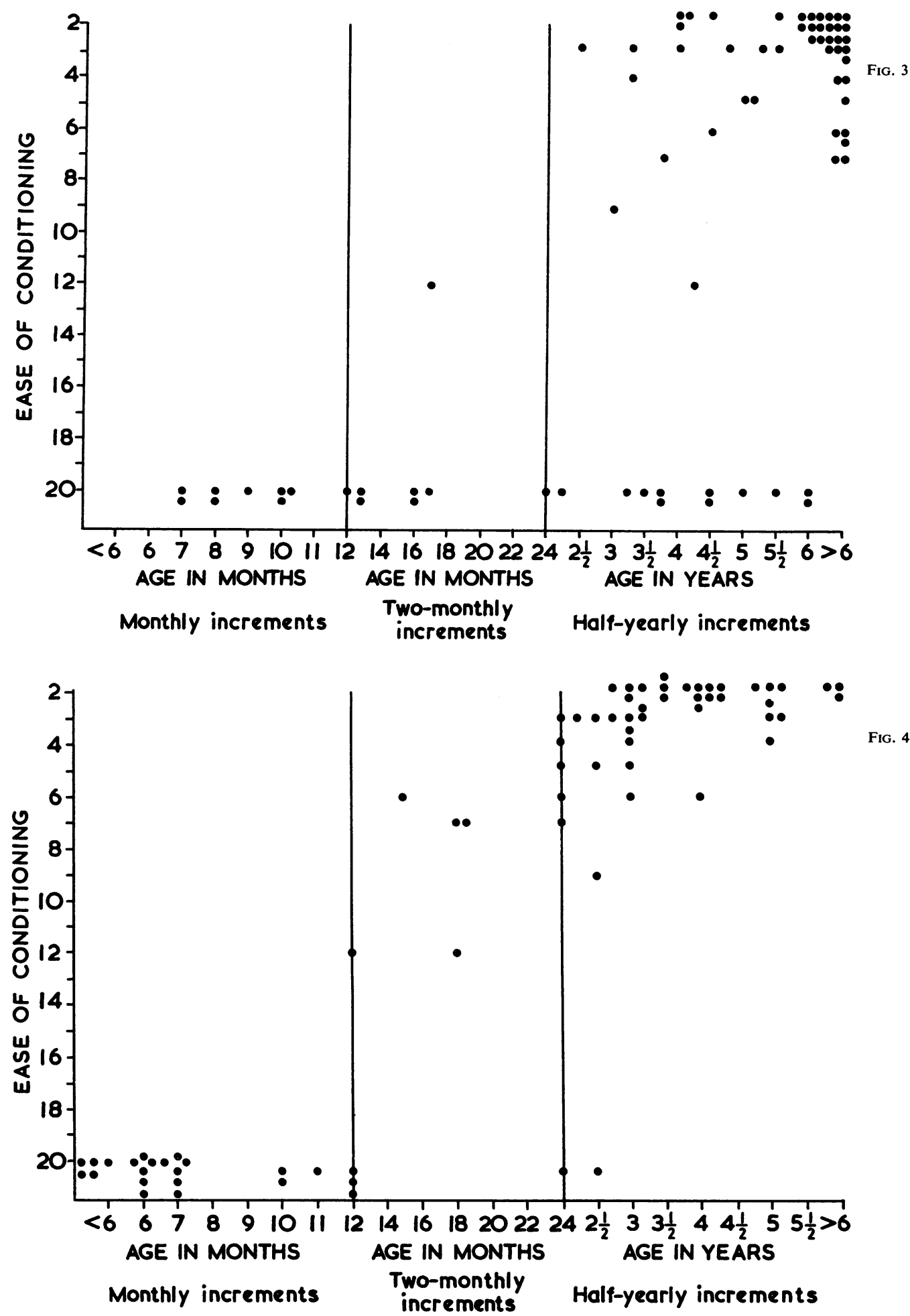

FIG. 3.-The puff test. Ease of conditioning compared with chronological age in 74 mentally defective children.

Fig. 4.-The puff test. Ease of conditioning compared with approximate mental age in 74 mentally defective children. 
Sometimes the end point was not clear-cut and the test had to be abandoned.

I found two abnormal reactions. The first was the 'stoic' reaction. After the first or second puff the child looked into the distance and appeared voluntarily to refuse to blink, even when the air flow was increased to 10 or more litres per minute. This reaction occurred four times in 155 normal, and once in 74 mentally retarded children over the age of 18 months.

The other special reaction I have termed the 'wait-for-it' reaction. This is very akin to what Pavlov called the 'what-is-it' or investigatory reflex (Pavlov, 1927, p. 12). The child obviously knew that he was about to have his face puffed, but took no avoiding action of any sort and seemed pleased when the puff came. Sometimes he opened his mouth as though expecting a spoon. On two occasions he blew back before the 'gun' was fired. The 'wait-for-it' reaction occurred five times in the normal children, but only in those under the age of 12 months. The 'wait-for-it' reaction occurred twice in mentally retarded children. One was a 4-year-old mongol with a mental age of from 12 to 18 months. She grizzled all the time the test was being performed until the twelfth puff. From then onward she stopped grizzling when the 'gun' was presented, laughed at the puff and then started grizzling again while waiting for the next puff. From the fifteenth puff onward she blew back at the puffer. She never blinked or screwed up her eyes. The other child was 5 years old, with a mental age of about 3 years. She showed a good conditioned eye blink at five, but from then on asked repeatedly when I was going to puff her face again. Two 10-year-old boys with low intelligence both opened their mouths as soon as the gun was presented. In each case the 'wait-for-it' reaction occurred in retarded children over the age of 4 years, whereas it only occurred in normal children under the age of 1 year. If the 'wait-for-it' reaction was well marked I took it as the conditioning end point, although it was not the expected conditioned reflex.

It is interesting to compare these results with those of Mateer (1918). She used Krasnogorski's (1913) method of allowing blindfolded children to hear a metronome and then giving them chocolate. By a mechanical method she recorded the movement of their throats as they swallowed saliva. She first tried the experiment on 50 unselected children, and estimated their intelligence afterwards. Her results are given in Table 2 and in graphic form in Fig. 5. She found a linear relationship between age and ease of conditioning for the ages of 1 to 5 years. Over that age the relationship broke down, perhaps
TABLE 2

EASE OF CONDITIONING COMPARED WITH CHRONOLOGICAL AGE IN 50 UNSELECTED CHILDREN*

\begin{tabular}{c|c|c|c}
\hline $\begin{array}{c}\text { No. of } \\
\text { Cases }\end{array}$ & $\begin{array}{c}\text { Age } \\
\text { (yrs) }\end{array}$ & $\begin{array}{c}\text { No. of Trials } \dagger \\
\text { (Average) }\end{array}$ & Range \\
\hline 5 & $1-2$ & $8 \cdot 0$ & $7-9$ \\
7 & $2-3$ & $6 \cdot 7$ & $6-8$ \\
6 & $3-4$ & $5 \cdot 3$ & $3-8$ \\
12 & $4-5$ & $3 \cdot 8$ & $3-5$ \\
8 & $5-6$ & $4 \cdot 1$ & $3-5$ \\
9 & $6-7$ & $5 \cdot 0$ & $3-7$ \\
3 & $7-8$ & $4 \cdot 3$ & $4-5$ \\
\hline
\end{tabular}

* (After Mateer, 1918.)

+ Three was the best result possible by Mateer's method and corresponds to the adult type of reaction.

because the older child, with his greater experience saw 'possibilities of variations in the procedure to which the younger child is oblivious'.

The graph culled from Mateer's figures (Fig. 5) and the scattergram of the present experiment (Fig. 2) both show that there is a relationship between ease of conditioning and age. Mateer repeated the experiment on 12 mentally defective children. Her final conclusions were that ease of conditioning is 'not directly proportional to mental ability but is also relative to chronological age'; but she felt that she had devised a 'fundamental test of the mental process'.

A very similar experiment to the one which I performed has also been described by Morgan and Morgan (1944). They puffed air into the eyes of babies and obtained a wink. At the next presentation five seconds later, they watched to see whether the baby would wink in anticipation of the puff or not. In either event a further puff was given. If the child did not learn the lesson assigned in the experiment by 100 presentations he was considered to have failed. Forty-two infants were treated; all children over the age of 65 days passed the test with one exception; all children under the age of 54 days failed the test; some passed and some failed between 54 and 65 days. The child over the age of 65 days who failed was 4 months old. At the age of 5 months a Cattel test was performed, and her I.Q. was recorded as being 76 . The authors state that to perform the test successfully a child must be old enough, and must be able to see. They also thought that if an infant over 65 days old failed to pass the test it might be due to inferior intelligence, but that they had insufficient evidence to verify or repudiate this hypothesis.

\section{Conclusion}

We can now consider the three questions which these experiments are designed to answer. 


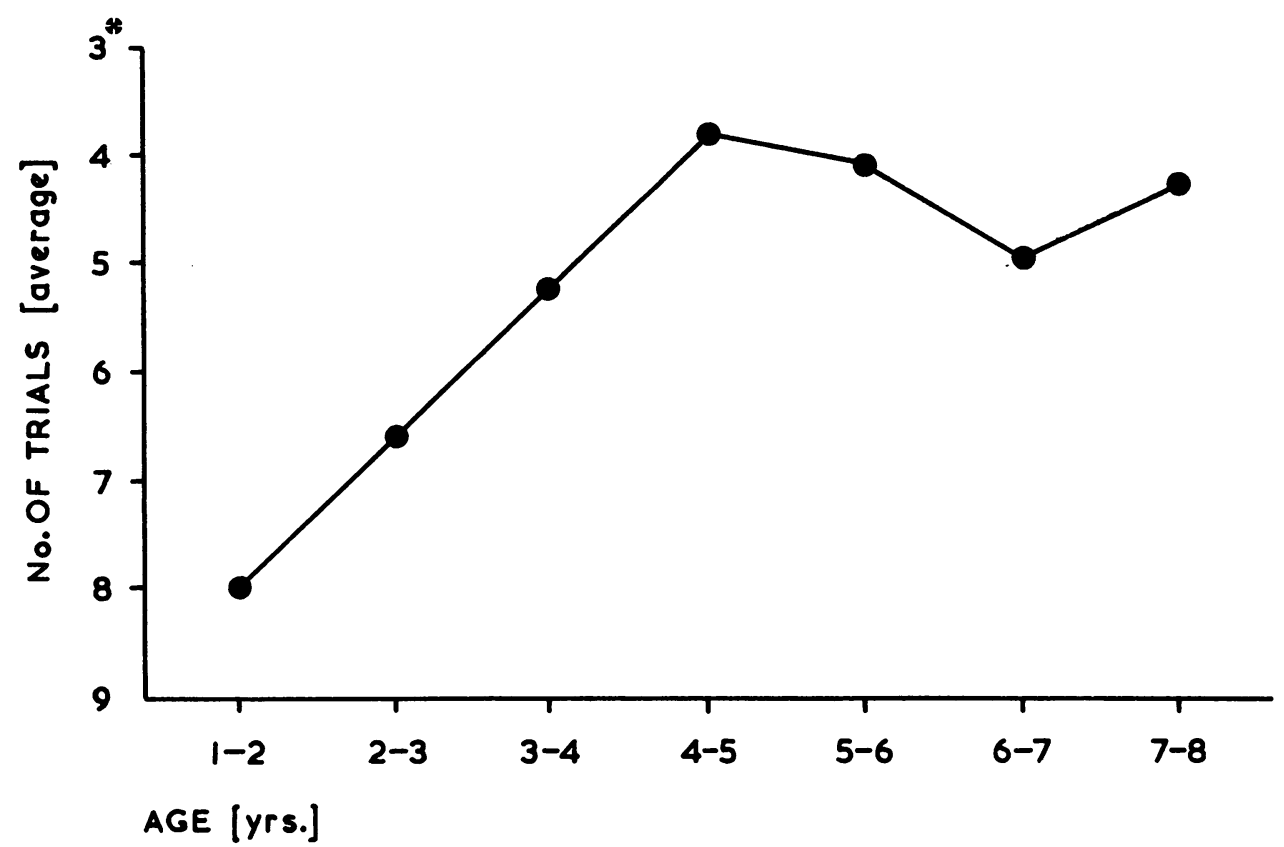

FIG. 5.-Ease of conditioning compared with chronological age in 50 unselected children. Graphic representation of Table 2 (from Mateer 1918); three was the best possible result by Mateer's method.

Mateer's experiments and mine, although using different techniques, both showed an almost linear relationship between ease of conditioning and age in mentally normal children up to about 5 years of age. Above this age the power of reasoning obscured the straightforward conditioned reflex response. The 'adult type' of reaction described above only occurred with adults who had not been told previously what to expect. I performed a small series of experiments on sophisticated medical students who had heard about the test, although they had not seen it in action. The results obtained were quite bizarre.

The experiments showed a relationship between ease of conditioning and mental age in mentally retarded children, although there was a much wider scatter in the results with mentally retarded than with normal children. This was probably due in part to the difficulty in measuring mental age with accuracy.

There is a formidable battery of developmental tests which can be used to measure the mental age of young children. Unfortunately most of these tests require either manipulative skill, such as walking or building a tower of bricks, or knowledge, which has to be learnt from others, such as the recognition of a picture or obedience to a command.
The puff test has the advantage that neither of these skills are required. It is therefore of particular value in testing the mental ability of children with some physical handicap such as spasticity or deafness. The following case reports illustrate this.

Case 1. This child, 2 years and 5 months old, had a mild right hemiplegia and was thought to be mentally defective. In the puff test she conditioned easily in two puffs, which is the adult-type of reaction and this made it improbable that she was grossly mentally defective; in fact, she was found to be completely deaf. Normal developmental testing had been virtually impossible owing to the dual disability.

Case 2. This boy of 8 months had mild kernikterus in the neonatal period due to Rhesus incompatibility. He was seen to smile at 4 weeks and at 6 weeks his motor development was described as 'better than average'. By 5 months, however, his motor development was very poor and he was regarded as being mentally retarded. There were no athetoid movements at that time. At 8 months he could not sit, had the head control of a 4-month-old baby, and did not vocalize. A puff test, however, gave a 'wait-for-it' reaction from 10 puffs onward. With each puff the boy gave a deep breath as many babies do, and from 13 puffs onward, gave a conditioned deep breath before each puff. ( $\mathrm{He}$ is the only child in whom I have observed this.) 
If 13 is taken as the end point, it is most unlikely that this baby is severely mentally retarded. This is confirmed by his early developmental history, and the fact that he has since been shown to be deaf and to be developing athetosis with hypotonia.

By using a tactile or auditory unconditioned stimulus the puff test could be modified for use in blind children.

The test must obviously be used in conjunction with other well-recognized tests of intelligence. In some cases the end point is too indefinite to be of any value. This is particularly so if the test is performed in distracting surroundings. The information it gives is limited, but the test is easy to perform, takes a short time, can be repeated if necessary, and occasionally gives information unobtainable in any other way. It is obvious that a great deal of further study is required, but it does seem that the test may prove to be of value either in itself, or as a basis for other tests.

\section{Summary}

A conditioned reflex has been established in a number of children under standard conditions. The reflex used was the eye blink when air was puffed into the child's eye.

The test was performed on 155 mentally normal children with the following results: Children of 6 months old and under could not be conditioned; over the age of 6 months conditioning became progressively easier until the typical adult response of immediate conditioning was reached at about 4 years of age.

Provisional results in 74 mentally defective children are also reported. As a group they were more difficult to condition than ordinary children of the same chronologial age. When speed of conditioning in the mentally defective children was correlated with their mental age, the ease of conditioning approximated to that of normal children, although there was a wider scatter.

It is suggested that the puff test can be used as a simple intelligence test. It has the following advantages: It is quick to perform, needs little apparatus, and only requires a minimum of co-operation from the child, and in addition requires no motor skill nor educational knowledge on the part of the child.
Two unusual reactions were noticed. In the 'stoic' reaction the child voluntarily refused to blink. This reaction occurred in children over the age of 18 months. In the 'wait-for-it' reaction which occurred in normal children under 12 months old, the child gave evidence that he knew that he was about to be puffed, but took no avoiding action. If well marked, this was taken as the end point of conditioning.

The puff test has been found to be of value in assessing the intelligence of young children with physical handicaps such as spasticity or deafness. Like any other intelligence test, it cannot be used alone, but in conjunction with other tests it should prove valuable.

Thanks are due to Dr. M. W. Partington who helped greatly in the initial stages of this investigation and to Dr. K. A. Rahimtulla for help in the later stages. I am indebted to Dr. T. Colver, Dr. Llewellyn Roberts, Dr. A. K. Black and Mr. J. W. Freeman who kindly allowed me to investigate children under their care in hospital, at infant welfare clinics and residential nurseries, and Miss de Newman who gave invaluable assistance at the Manor Clinic, Sheffield; to Mr. W. B. Birch of the Institute of Education, University of Sheffield, for helpful criticisms, and to Professor R. S. Illingworth for sugyesting this investigation.

\section{REFERENCES}

Aldrich, C. A. (1928). A new test for hearing in the newborn. The conditioned reflex. Amer. $J$. Dis. Child, 35, 36

Birch, H. G. and Demb, H. (1959). The formation and extinction of conditioned reflexes in 'brain-damaged' and mongoloid children. J. nerv. ment. Dis., 129, 162.

Bordley, J. E. and Hardy, W. G. (1949). A study in objective audiometry with the use of a psychogalvanometric response. Ann. Otol. (St. Louis), 58, 751.

Campbell, A. A. and Hilgard, E. R. (1936). Individual differences in ease of conditioning. J. exp. Psychol., 19, 561 .

Dix, M. R. and Hallpike, C. S. (1947). The peep-show. A new technique for pure-tone audiometry in young children. Brit. med. $J ., 2,719$

Gesell, A. (1948). Studies in Child Development, pp. 65-79. Harper, New York.

and Ilg, F. L. (1937). Feeding Behavior in Infants, p. 53. Lippincott, Philadelphia.

Hilliard, L. T. and Kirman, B. H. (1957). Mental Deficiency, p. 321. Churchill, London.

Kodman, F., Jr., Fein, A. and Mixson, A. (1959). Psychogalvanic skin response audiometry with severe mentally retarded children. Amer. J. ment. Defic., 64, 131.

Krasnogorski, N. (1913). Über die Grundmechanismen der Arbeit der Grosshirnrinde bei Kindern. Jb. Kinderheilk. n.s. 28, 373.

Mateer, F. (1918). Child Behavior. A Critical and Experimental Study of Young Children by the Method of Conditioned Reflexes. Gordon Press, Boston.

Morgan, J. J. B. and Morgan, S. S. (1944). Infant learning as a developmental index. J. Genet. Psychol., 66, 281.

Pavlov, I. P. (1927). Conditioned Reflexes, trans. G. V. Anrep. Milford, London.

Statten, P. and Wishart, D. E. S. (1956). Pure-tone audiometry in young children; psychogalvanic-skin-resistance and peep-show. young children; psychogalvanic-s
Ann. Otol. (St. Louis), 65, 511 .

Wenger, M. A. (1943). "Conditioned responses in human infants." In Child Behavior and Development, ed. R. G. Barker, J. S. Kounin and H. F. Wright, pp. 67-86. McGraw-Hill, New York. 